\title{
Relações planta-animal em ambiente pastoril heterogêneo: padrões de deslocamento e uso de estações alimentares
}

\author{
Edna Nunes Gonçalves ${ }^{1}$, Paulo César de Faccio Carvalho ${ }^{1}$, Thais Devincenzi ${ }^{1}$, Marília \\ Lazzarotto Terra Lopes $^{1}$, Fabiana Kellermann de Freitas ${ }^{1}$, Aino Victor Ávila Jacques ${ }^{1}$
}

1 Universidade Federal do Rio Grande do Sul (UFRGS) - Departamento de Plantas Forrageiras e Agrometeorologia, Caixa Postal 776, CEP 91501- 970, Porto Alegre, RS.

RESUMO - Avaliou-se como o padrão de deslocamento e de utilização de estações alimentares podem ser afetados por alturas de manejo de 4, 8, 12 e $16 \mathrm{~cm}$ numa pastagem nativa. Utilizou-se um delineamento inteiramente casualizado, com quatro tratamentos e duas repetições no tempo e no espaço. Os animais experimentais foram avaliados por meio de testes de pastejo de 45 minutos, para determinação dos número de bocados, número de estações alimentares e número de passos, utilizando-se contadores, com exceção do número de bocados, que foi registrado pelo aparelho IGER Behaviour Recorder. Observou-se correlação positiva entre altura do pasto e massa de forragem e correlação negativa entre alturas do pasto e densidade de forragem. As variáveis avaliadas diferiram entre bezerras e ovelhas. O número de estações alimentares por minuto diminuiu de forma quadrática com o aumento da altura do pasto. O número de bocados por estação alimentar visitada e o tempo por estação alimentar aumentaram de forma quadrática com o aumento da altura do pasto e foram afetados negativamente pela baixa densidade de forragem nos estratos superiores das maiores alturas do pasto. Na altura de $12 \mathrm{~cm}$, as bezerras executaram mais bocados por estação alimentar e permaneceram mais tempo em cada estação alimentar; o mesmo foi observado na altura de $8 \mathrm{~cm}$ para as ovelhas. À medida que menos estações alimentares foram utilizadas, como resposta às variáveis anteriores, os animais andaram mais a passos mais lentos. Em alturas do pasto entre 8 e $12 \mathrm{~cm}$, os animais permanecem mais tempo pastejando nas estações alimentares e percorrem distâncias maiores à procura de novos locais para o pastejo.

Palavras-chave: bezerras, bocados, estrutura do pasto, ovelhas, pastagem nativa

\section{Plant-animal relationships in a heterogeneous pastoral environment: displacement patterns and feeding station use}

\begin{abstract}
This study assessed how the displacement patterns and feeding station used can be affected by sward heights of 4, 8, 12 and $16 \mathrm{~cm}$. A randomized complete design was used with two replication in time and space. The animals were evaluated by 45- minute grazing tests, to determine the number of bites, number of feeding stations and number of steps using counters, except for number of bites, which was registered by the IGER Behaviour Recorder device. A positive correlation was observed between sward height and herbage mass, and negative correlation between sward height and herbage bulk density. Differences between female calves and ewes were observed in all variables evaluated. The number of feeding station per minute decreased quadratically with increasing sward height. The number of bites per feeding station and time per feeding station increased quadratically with increasing sward height and were affected negatively by the lower herbage bulk density in the upper strata of the higher sward heights. Female calves, at $12 \mathrm{~cm}$ sward height, carried out more bites per feeding station and remained longer at each feeding station. The same behaviour was observed for ewes at $8 \mathrm{~cm}$ sward height. As less feeding stations were used, as a response to the previous variables, the animals walked more with slower steps. Thus, at sward heights between 8 and $12 \mathrm{~cm}$ the animals remained more time grazing each feeding station and covered longer distances searching for new grazing sites.
\end{abstract}

Key Words: bite, calves, ewes, native pasture, sward structure

\section{Introdução}

As ações dos animais são organizadas de forma hierárquica e em diferentes escalas; iniciam-se no âmbito da paisagem, passam pelos níveis de comunidade, patch, estação alimentar e planta, até chegar ao bocado (Carvalho, 1997).

Define-se como estação alimentar o semicírculo hipotético onde o animal toma um ou mais bocados sem a necessidade de deslocar-se (sem mover suas patas dianteiras) 
e alcança o alimento com movimentos da cabeça. O patch pode ser definido como um agregado de estações alimentares, cuja taxa de ingestão instantânea (o quociente entre a massa do bocado e o tempo para a sua formação) são distintos entre si, o que permitiria aos animais escolher novos locais de pastejo (Ruyle \& Dwyer, 1985). A comunidade, então, representa um agregado de patches e a paisagem um agregado de diferentes comunidades.

Ao longo do processo de pastejo, o animal busca as estações alimentares enquanto caminha. Do total de estações alimentares existentes numa pastagem, os animais selecionam umas e rejeitam outras por meio de atributos que acarretam seletividade. Portanto, o tempo de procura por estações alimentares dependerá da velocidade de deslocamento, da quantidade de estações alimentares por unidade de superfície e da seletividade (Ungar \& NoyMeir, 1988), além da movimentação do animal ao longo do ambiente de pastejo e todos os processos sensoriais e cognitivos envolvidos na decisão de se colher aquele bocado dentre vários outros possíveis (Ungar, 1996).

Todo o processo de pastejo anteriormente descrito tem sido estudado, de forma predominante, em pastagens monoespecíficas. No caso de ambientes pastoris heterogêneos, como é o caso das pastagens nativas, a quantidade de informações de que o animal deve dispor para acionar seus mecanismos de decisão é muito mais complexa. Com isso, a procura e seleção de estações alimentares nesses ambientes poderiam alcançar patamares elevados de dificuldade, se tornando um impedimento ao alcance dos requerimentos nutricionais dos animais. Desta forma, o objetivo com este trabalho foi avaliar o efeito da estrutura de uma pastagem nativa, representada por diferentes alturas do pasto, no padrão de deslocamento e na forma de utilização das estações alimentares por bovinos e ovinos.

\section{Material e Métodos}

O experimento foi conduzido em área de pastagem nativa, pertencente à Estação Experimental Agronômica (EEA) da Universidade Federal do Rio Grande do Sul (UFRGS), situada no km 146 da BR - 290, município de Eldorado do Sul - RS (3005 '52" S, 51 3039'08" W e altitude média de 46 metros) compreendendo a região fisiográfica da Depressão Central. De acordo com a Classificação de Solos (Embrapa, 1999), o tipo de solo predominante pertence à classe taxonômica Plintossolo e caracteriza-se por solos mediamente profundos, mal drenados, de textura franco-arenosa, ácidos, com baixos teores de matéria orgânica, de fósforo e de saturação de bases. O clima da região é do tipo Cfa, subtropical úmido com verão quente, segundo classificação de Köppen. A metodologia utilizada para a caracterização botânica da pastagem foi baseada na classificação de Braun-Blanquet (1979). Para isso utilizaram-se três quadrados de $0,25 \mathrm{~m}^{2}$ por unidade experimental onde foram determinadas as principais espécies constituintes do pasto, como se seguem: Paspalum notatum e Axonopus affinis, com cobertura de 1/4 a 1/2 da superfície; e Desmodium incanum e Paspalum plicatulum, com cobertura escassa ou cobrindo entre 1/10 e 1/4 da superfície.

Estudou-se o efeito de quatro alturas do pasto, as quais corresponderam a 4, 8, 12 e 16 cm, com duas repetições de piquete e duas repetições no tempo, totalizando 16 testes de pastejo para cada espécie animal (ovelhas e bezerras), realizados no período de 24/10/2006 a 4/12/2006. A área de cada um dos oito piquetes correspondeu a $187 \mathrm{~m}^{2}$. Para a realização dos testes de pastejo, foram utilizadas quatro bezerras de raça indefinida, com peso vivo médio de $160 \mathrm{~kg}$ ( $\pm 4 \mathrm{~kg}$ ) e com largura da arcada dentária medindo $60 \mathrm{~mm}$ ( $\pm 2 \mathrm{~mm}$ ) e quatro ovelhas da raça Suffolk, com peso vivo médio de $62 \mathrm{~kg}$ ( $\pm 4 \mathrm{~kg}$ ) e largura da arcada dentária medindo $35 \mathrm{~mm}$ ( $\pm 2 \mathrm{~mm})$. Visando à obtenção do efeito de grupo descrito por Arnold (1987), foram adicionadas mais duas bezerras (segundo Rind \& Phillips, 1999) e quatro ovelhas (segundo Penning et al., 1993), quando de seus respectivos testes de pastejo, apenas para compor o lote. Em cada dia de avaliação, foram feitos os testes de pastejo para determinação das variáveis do processo de deslocamento e determinadas as variáveis de caracterização da estrutura do pasto na unidade experimental avaliada. Desta forma, a primeira fase foi destinada aos testes de pastejo com as bezerras nas quatro alturas do pasto e suas respectivas repetições ( 8 dias $=4$ alturas de pasto $\times 2$ repetições) e, na segunda fase, utilizaram-se mais 8 dias para as avaliações com as ovelhas. As duas fases foram repetidas para ambas as espécies animais, com a finalidade de obter duas repetições no tempo, totalizando 32 dias de avaliação. Os testes de pastejo iniciavam às 14 horas e se estendiam até as 17 horas.

A estrutura do pasto foi moldada previamente ao longo de três anos por meio de pastejo controlado. Isto porque não somente as alturas absolutas devessem ser objeto de estudo, mas também as suas estruturas respectivas, condição que seria atingida somente com a manutenção dos tratamentos por prolongado período de tempo. Para a medição da altura do pasto, utilizou-se um bastão graduado (sward-stick), cujo marcador corre por uma "régua" até tocar a primeira lâmina foliar, procedendo-se então a leitura 
da altura (Barthram, 1985). As medidas foram realizadas de forma aleatória, totalizando 50 pontos em cada unidade experimental (piquete). Para garantir que o tempo de permanência dos animais no piquete não afetasse a estrutura dos tratamentos, foram realizadas 50 medidas de altura com Sward-Stick antes e depois dos testes de pastejo, considerando válidos apenas aqueles testes com variação máxima de 5\% em relação à altura inicial.

Para a quantificação da massa de forragem, foram coletadas duas amostras do pasto por unidade experimental antes dos testes de pastejo. Para isso, utilizou-se um retângulo metálico, com área de $0,1230 \mathrm{~m}^{2}(30 \times 41 \mathrm{~cm})$. As amostras de forragem foram cortadas com tesoura, no nível do solo, colocadas em estufa de circulação forçada de ar a $65^{\circ} \mathrm{C}$ até peso constante, sendo posteriormente pesadas para obtenção da massa seca, expressa em kg/ha de MS. As amostras foram ainda separadas em seus componentes morfológicos para obtenção da fração massa de lâminas foliares dentro da massa de forragem. O quociente entre as massas de forragem e de lâminas foliares pela altura do pasto compôs o cálculo de suas respectivas densidades volumétricas, expressas em $\mathrm{mg} / \mathrm{cm}^{3}$ de MS.

Foi realizado um teste de pastejo por dia, de acordo com o seguinte protocolo experimental: após submeter os animais a um jejum de sólidos e líquidos por um período de cinco horas antes do início dos testes de pastejo, os quatro animais experimentais foram divididos em dois grupos. $\mathrm{O}$ primeiro grupo (animais A e B) foi levado àárea experimental junto aos animais acompanhantes, por um período de 45 minutos, enquanto o segundo grupo (animais C e D) permaneceu, por um mesmo período, em uma área não vegetada adjacente às unidades experimentais (área de espera) impossibilitados de consumir água e alimentos sólidos. Os animais A e B, que anteriormente foram avaliados nos testes de pastejo, passaram para a área de espera e os animais C e D, por sua vez, passaram para os testes de pastejo, repetindo-se os procedimentos anteriores.

Para determinação do número de bocados foi utilizado um aparelho para monitoramento automático dos movimentos mandibulares (IGER Behaviour Recorder). Esse aparelho registra os movimentos mandibulares totais, através de um sensor localizado abaixo da mandíbula, e os diferenciam em movimentos de apreensão (bocados) e de mastigação. Posteriormente estes dados foram analisados pelo Software Graze.

Os passos foram contados utilizando-se como critério a movimentação das patas dianteiras e cada estação alimentar foi definida como um semicírculo hipotético onde o animal pasteja sem mover suas patas dianteiras, alcançando o alimento com movimentos da cabeça (Ruyle \& Dwyer, 1985).

Durante os testes de pastejo cada animal foi monitorado por um avaliador previamente treinado, que verificou o número total de estações alimentares e o número total de passos dados pelo animal durante o teste de pastejo, utilizando-se para isso um contador manual. A partir dos dados coletados em campo, puderam-se determinar as seguintes variáveis que compõem o processo de deslocamento dos animais em pastejo: a) número de estações alimentares por minuto: dado pelo quociente entre o número total de estações alimentares e a duração, em minutos, do teste de pastejo; b) passos entre estações alimentares: razão entre o número total de passos pelo número de estações alimentares visitadas durante o teste de pastejo; c) bocados por estação alimentar: dado pelo quociente entre o número total de bocados (obtido pelo aparelho IGER) e o número total de estações alimentares; d) taxa de deslocamento: número total de passos dividido pela duração, em minutos, dos testes de pastejo; e finalmente, e) tempo por estação alimentar: quociente entre a duração dos testes de pastejo, em segundos, pelo número total de estações alimentares visitadas.

O delineamento estatístico utilizado foi o inteiramente casualizado, com quatro tratamentos e duas repetições no tempo e no espaço. Para melhor avaliar as variáveis repetidas no tempo, utilizou-se o procedimento MIXED e, quando detectadas diferenças entre as médias, estas foram comparadas pelo teste t de Student (PDIFF). Foi utilizado um nível de significância de $10 \%$ para a avaliação dos resultados. Também foram realizadas regressões até terceira ordem e análises de correlação a partir do pacote estatístico Statistical Analysis System - SAS (SAS, 1999). O modelo matemático geral referente à análise das variáveis estudadas foi representado por:

$$
\begin{aligned}
& \mathrm{y}_{\mathrm{ijkl}}=\mu+\tau_{\mathrm{i}}+\beta_{\mathrm{j}}+\alpha_{\mathrm{k}}+(\beta \alpha)_{\mathrm{jk}}+(\tau \alpha)_{\mathrm{ik}}+\gamma_{\mathrm{l}}+(\tau \gamma)_{\mathrm{il}}+(\alpha \gamma)_{\mathrm{kl}} \\
& +(\tau \alpha \gamma)_{\mathrm{ikl}}+\varepsilon_{\mathrm{ijkl}}
\end{aligned}
$$

em que: $\mathrm{y}_{\mathrm{ijkl}}=$ variáveis dependentes; $\mu$ = média inerente a todas as observações; $\tau_{\mathrm{i}}=$ efeito do i-ésimo tratamento (altura do pasto); $\beta_{\mathrm{j}}=$ efeito da j-ésima repetição; $\alpha_{\mathrm{k}}=$ efeito da k-ésima espécie animal; $(\beta \alpha)_{\mathrm{jk}}=$ efeito aleatório atribuído à interação entre repetição e espécie animal; $(\tau \alpha)_{\mathrm{ik}}=$ efeito da interação entre tratamento e espécie animal; $\gamma_{1}=$ efeito do l-ésimo tempo observado; $(\tau \gamma)_{\mathrm{il}}=$ efeito da interação entre tratamento e tempo; $(\alpha \gamma)_{\mathrm{kl}}=$ efeito da interação espécie animal $\times$ tempo; $(\tau \alpha \gamma)_{\mathrm{ikl}}=$ efeito da interação $\times$ altura, espécie animal $\times$ tempo; e $\varepsilon_{\mathrm{ijkl}}=$ erro aleatório residual (variação do acaso sobre as observações). 


\section{Resultados e Discussão}

As alturas médias reais do pasto usadas para avaliar o padrão de deslocamento e de utilização de estações alimentares diferiram entre si, garantindo a independência dos mesmos quanto as variáveis avaliadas. A variação máxima pré-estabelecida, de 5\%, para a diferença de altura do pasto entre a entrada e a saída dos animais foi atingida (Tabela 1), indicando, que na média, a estrutura do pasto não foi alterada ao longo de cada teste de pastejo.

Quanto maiores as massas de forragem e de lâminas foliares (Figura 1 e Tabela 1) maiores foram as alturas do pasto, que mantiveram estreita relação de $50 \%$ de lâminas foliares na massa de forragem, refletindo o efeito da altura de manejo sobre a forragem disponível (Penning et al., 1991). As densidades de forragem e de lâminas foliares (Figura 1 e Tabela 1), por sua vez, reduziram com o aumento da altura do pasto. Vários autores têm demonstrado que a taxa de surgimento de folhas tende a diminuir com o aumento da altura da planta devido ao maior comprimento da bainha das folhas sucessivas, o que aumentaria o comprimento de lâminas foliares e reduziria o número de folhas por perfilho, e consequentemente haveria menor perfilhamento (Lemaire \& Chapman, 1996; Nabinger, 1997; Duru \& Ducrocp, 2000). No entanto, esse aumento no tamanho parece estar mais associado ao aumento no comprimento da lâmina que em sua largura, pelo menos quando falamos em Paspalum notatum, pois segundo Cruz et al. (2007), um aumento no tamanho das folhas desta planta não resultou em mudanças no conteúdo de matéria seca de lâminas ou na sua área específica, o que pode ser este o motivo da redução da densidade volumétrica com o aumento da altura do pasto.

Houve uma correlação positiva entre a altura da pastagem e a massa de forragem $(r=0,86)$ e correlação negativa entre altura do pasto e a densidade do pasto $(r=-0,81)$. Altas correlações entre estas variáveis são normalmente encontradas em pastagens cultivadas, com características estruturais mais homogêneas. No entanto, em trabalhos realizados por Santos et al. (2004) e Carassai et al. (2008), em pastagem análoga a deste experimento, em que o manejo incluía roçadas e adubação do pasto, também foram encontrados elevados coeficientes de correlação entre a altura do pasto e a massa de forragem ( $\mathrm{r}=0,70$ e 0,87 , respectivamente), evidenciando a importância do manejo adequado nas características estruturais do pasto.

A densidade de forragem foi, entre as variáveis do pasto avaliadas, a que teve efeito mais significativo na resposta do número de bocados por estação alimentar (coeficiente de correlação = -0,76). Segundo Tharmaraj et al. (2003), a redução da densidade de forragem representa maior dispersão de lâminas foliares no plano superior do pasto e maior tempo destinado à apreensão e manipulação da forragem, o que, de acordo com Carvalho et al. (2001) limitaria a apreensão de novos bocados. Esse efeito de redução da densidade da forragem foi sentido a partir de alturas distintas para as espécies animal avaliadas, devido às diferenças intrínsecas da largura da arcada dentária, bem como na diferença quanto à forma de apreensão da forragem entre ovinos (lábios) e bovinos (língua) (John \& Milne, 1991) e que afetaram, por sua vez, o número de bocados em cada

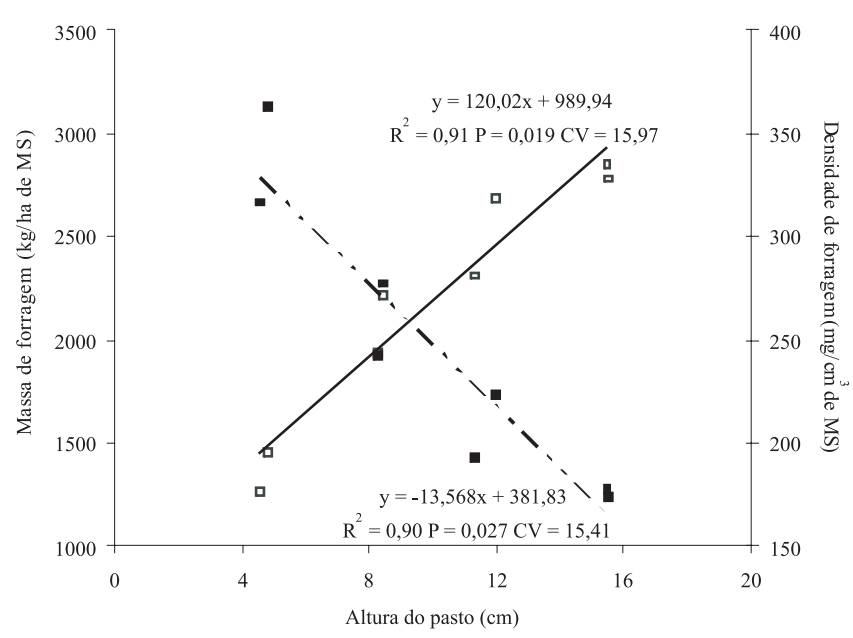

Figura 1 - Relação da massa de forragem ( $\square$ ) e da densidade de forragem ( $\mathbf{\square})$ em pastagem nativa em diversas alturas do pasto.

Tabela 1 - Altura do pasto, massa de lâminas foliares, densidade de lâminas foliares, de pastagem nativa em diversas alturas do pasto

\begin{tabular}{|c|c|c|c|c|c|c|c|}
\hline \multirow[t]{2}{*}{ Item } & \multicolumn{4}{|c|}{ Altura do pasto } & \multirow[t]{2}{*}{$\mathrm{R}^{2}$} & \multirow[t]{2}{*}{$\mathrm{T}^{\mathrm{a}}$} & \multirow[t]{2}{*}{$\mathrm{DPM}^{\mathrm{b}}$} \\
\hline & $4 \mathrm{~cm}$ & $8 \mathrm{~cm}$ & $12 \mathrm{~cm}$ & $16 \mathrm{~cm}$ & & & \\
\hline Altura de entrada (cm) & 4,8 & 8,5 & 12,2 & 15,7 & 0,99 & 0,001 & 0,44 \\
\hline Altura de saída $(\mathrm{cm})$ & 4,7 & 8,1 & 11,9 & 15,2 & 0,97 & 0,009 & 0,63 \\
\hline Altura média real $(\mathrm{cm})$ & 4,7 & 8,3 & 12,0 & 15,4 & 0,95 & 0,002 & 0,55 \\
\hline Massa de lâminas foliares (kg/ha de MS) & 632 & 1040 & 1284 & 1400 & 0,69 & 0,003 & 192,62 \\
\hline Densidade de lâminas foliares $\left(\mathrm{mg} / \mathrm{cm}^{3}\right.$ de $\mathrm{MS}$ ) & 1,58 & 1,30 & 1,07 & 0,87 & 0,57 & 0,011 & 0,22 \\
\hline
\end{tabular}

a Teste t de Student (PDIFF).

b Desvio-padrão da média. 
estação alimentar. Desta forma, foi possível observar que as ovelhas após a altura do pasto de $8 \mathrm{~cm}$ e as bezerras a partir de $12 \mathrm{~cm}$ (Tabela 2) reduziram o número de bocados em cada estação alimentar, provavelmente como consequência da menor densidade de forragem e da maior dificuldade de apreensão da forragem. Segundo Silva \& Carvalho (2005), a captura da lâmina individual pode ocorrer não somente pela baixa densidade delas no horizonte pastejável, mas também por uma relação desfavorável entre as dimensões da maxila.

O tempo de permanência nas estações alimentares esteve fortemente associado ao número de bocados por estação alimentar em ambas as espécies animais $(r=0,81)$, o que significa que o animal, ao reconhecer um local como "rico" em bocados potenciais, permaneceria colhendo bocados até o ponto em que a quantidade de forragem diminuísse e a taxa de consumo se igualasse à média de consumo da pastagem, abandonando-a em seguida, em busca de um novo local de pastejo (Charnov, 1976). Em experimento com bovinos em pastagem de Setaria lutescens, Wallis de Vries et al. (1999), observaram 7 bocados por estação alimentar, valor semelhante ao intervalo de 6 a 10 encontrado por Palhano et al. (2006) para bovinos em pastagem de capim-mombaça, e de 6 a 9 bocados por estação alimentar para ovinos em pastagem de capim-dos-pomares (Roguet et al., 1998). Rook et al. (2004) encontraram valores médios de 5,3 segundos por estação alimentar, com ovelhas pastejando azevém-perene (Lolium perenne L.).

Considerando haver um tempo fixo para a apreensão do bocado, independentemente da massa do bocado, o tempo para execução de cada bocado depende do tempo de mastigação (Prache \& Peyraud, 1997) e, por isso, à medida que os animais colheram mais bocados e bocados mais pesados, aumentou o tempo de permanência em cada estação.

Como resposta ao maior tempo de permanência nas estações alimentares, os animais passaram a estabelecer menor número de estações alimentares por minuto. Esse comportamento dos animais pode ser explicado pela maior massa do bocado (Carvalho, 1997), obtida em pastos que aliam massa e densidade de forragem adequadamente distribuídos. Ainda segundo Prache \& Peyraud (2001), essa situação pode não motivá-los à troca de estação alimentar, o que somente ocorreria se houvesse diminuição na massa de forragem e/ou percepção de melhores oportunidades de consumo em outros locais do pasto.

Tanto o número de passos entre estações alimentares quanto a taxa de deslocamento apresentaram diferença entre bezerras e ovelhas ( $\mathrm{P}=0,0178$ e $\mathrm{P}=0,0098$, respectivamente para número de passos entre estações e taxa de deslocamento). Independentemente da espécie animal, nas menores alturas do pasto os animais andaram menos entre estações alimentares e se deslocaram mais rapidamente. Segundo Roguet et al. (1998), em situações de abundância de forragem, os animais têm altas taxas de ingestão e mastigam bocados de alta massa enquanto caminham distâncias mais longas, dispensando mais tempo para a procura dos sítios de pastejo preferidos. Nessas condições, o último bocado de uma estação ainda possui massa elevada e o tempo correspondente de mastigação permite ao animal deslocar-se enquanto mastiga. O mesmo padrão de comportamento foi observado em novilhas em pastagens de capim-mombaça (Palhano et al., 2006).

Tabela 2 - Processo de deslocamento e procura por estações alimentares de bezerras e ovelhas em campo nativo em diversas alturas do pasto

\begin{tabular}{|c|c|c|c|c|c|c|c|c|}
\hline \multirow[t]{2}{*}{ Variável } & \multicolumn{4}{|c|}{ Altura do pasto } & \multirow[t]{2}{*}{ Modelo $^{\mathrm{a}}$} & \multirow[t]{2}{*}{$\mathrm{P}$} & \multirow[t]{2}{*}{$\mathrm{R}^{2}$} & \multirow[t]{2}{*}{$\mathrm{CV}$} \\
\hline & $4 \mathrm{~cm}$ & $8 \mathrm{~cm}$ & $12 \mathrm{~cm}$ & $16 \mathrm{~cm}$ & & & & \\
\hline \multicolumn{9}{|c|}{ Estações alimentares por minuto } \\
\hline Bezerras & 13,7 & 9,5 & 7,0 & 8,7 & Q & $<0,0001$ & 0,876 & 10,55 \\
\hline Ovelhas & 19,0 & 7,5 & 9,7 & 11,2 & Q & 0,0001 & 0,791 & 18,58 \\
\hline \multicolumn{9}{|c|}{ Passos entre estações alimentares } \\
\hline Bezerras & 1,1 & 1,3 & 1,8 & 1,2 & Q & 0,0057 & 0,498 & 19,18 \\
\hline Ovelhas & 1,1 & 2,4 & 1,6 & 1,2 & $\mathrm{Q}$ & 0,0009 & 0,620 & 22,15 \\
\hline \multicolumn{9}{|c|}{ Bocados por estação alimentar } \\
\hline Bezerras & 4,8 & 6,4 & 7,8 & 7,2 & Q & 0,0182 & 0,695 & 12,35 \\
\hline Ovelhas & 4,6 & 8,9 & 8,4 & 7,8 & Q & 0,0008 & 0,712 & 13,21 \\
\hline \multicolumn{9}{|c|}{ Taxa de deslocamento (passos/minuto) } \\
\hline Bezerras & 14,5 & 13,0 & 12,0 & 10,5 & $\mathrm{~L}$ & 0,0023 & 0,497 & 12,50 \\
\hline Ovelhas & 20,5 & 17,7 & 15,7 & 14,2 & $\mathrm{~L}$ & 0,0003 & 0,649 & 10,17 \\
\hline \multicolumn{9}{|c|}{ Tempo por estação alimentar (segundos) } \\
\hline Bezerras & 4,3 & 6,4 & 8,7 & 6,9 & Q & 0,0006 & 0,788 & 12,92 \\
\hline Ovelhas & 3,1 & 7,9 & 6,4 & 5,4 & $\mathrm{Q}$ & 0,0002 & 0,706 & 17,91 \\
\hline
\end{tabular}

${ }^{\mathrm{a}} \mathrm{L}$ = linear; $\mathrm{Q}$ = quadrática 


\section{Conclusões}

Os padrões de deslocamento e procura dos animais em pastejo são afetados pela estrutura do campo nativo. Em alturas do pasto entre 8 e $12 \mathrm{~cm}$ de altura, os animais permanecem mais tempo pastejando nas estações alimentares e percorrem distâncias maiores à procura por novos locais para o pastejo.

\section{Literatura Citada}

ARNOLD, G.W. Grazing behaviour. In: SNAYDON, R.W. (Ed.) Managed grassland: analytical studies. Amsterdam: Elsiever, 1987. p.129-135.

BARTHRAM, G.T. Experimental techniques: the HFRO sward stick. In: ALCOCK, M.M. (Ed.) Biennial report of the Hill Farming Research Organization. Midlothian: Hill Farming Research Organization, 1985. p.29-30.

BRAUN-BLANQUET, J. Fitosociologia. Bases para el estudio de las comunidades vegetales. Madrid: Ediciones Blume, 1979. 820p.

CARASSAI, I.J.; NABINGER, C.; CARVALHO, P.C.F. et al. Recria de cordeiras em pastagem nativa melhorada submetida à fertilização nitrogenada. 1. Dinâmica da pastagem. Revista Brasileira de Zootecnia, v.37, n.8, p.1338-1346, 2008.

CARVALHO, P.C.F. A estrutura da pastagem e o comportamento ingestivo de ruminantes em pastejo. In: JOBIM, C.C.; SANTOS, G.T.; CECATO, U. (Eds.) Simpósio sobre avaliação de pastagens com animais. 1.ed. Maringá: Coopergraf Artes Gráficas Ltda., 1997. p.25-52.

CARVALHO, P.C.F.; MARÇAL, G.K.; RIBEIRO FILHO, et al. Pastagens altas podem limitar o consumo dos animais. In: REUNIÃO ANUAL DA SOCIEDADE BRASILEIRA DE ZoOtecniA, 38., 2001, Piracicaba. Anais... Piracicaba: Sociedade Brasileira de Zootecnia, 2001. p.265-268.

CHARNOV, E.L. Optimal foraging: the marginal value theorem. Theoretical Population Biology, v.9, n.1, p.129-136, 1976.

CRUZ, P.; QUADROS, F.L.F.; THEAU, J.P. et al. Leaf traits as functional descriptors of the intensity of continuous grazing in native grasslands in the south of Brazil. Rangeland Ecology and Management. Wheat Ridge: Society for Range Management, 2009. (no prelo).

DURU, M.; DUCROCP, H. Growth and senescence of the successive grass leaves on a tiller ontogenic development and effect of temperature. Annals of Botany, v.85, n.2, p.635-643, 2000.

EMPRESA BRASILEIRA DE PESQUISA AGROPECUÁRIA EMBRAPA. Centro Nacional de Pesquisa do Solo - CNPS. Sistema Brasileiro de Classificação de Solos. Rio de Janeiro: Embrapa, 1999. 412p.

LEMAIRE, G.; CHAPMAN, D. Tissue flows in grazed plants communities. In: HODGSON, J; ILLIUS, A.W. (Eds.) The ecology and management of grazing systems. Wallingford: CAB INTERNATIONAL, 1996. p.3-36.

JOHN, A.; MILNE, A. Diet selecion by grazing animals. In: NUTRITION SOCIETy, 50., 1991, London. Proceedings... London, 1991. p.77-85.
NABINGER, C. Princípios da exploração intensiva de pastagens. In: SIMPOSIO SOBRE MANEJO DA PASTAGEM, 13., 1996, Piracicaba. Anais... Piracicaba: Fundação de Estudos Agrários Luiz de Queiroz, 1997. p.15-95.

PALHANO, A.L.; CARVALHO, P.C.F.; DITTRICH, J.R. Padrões de deslocamento e procura por forragem de novilhas leiteiras em pastagem de capim-mombaça. Revista Brasileira de Zootecnia, v.35, n.6, p.2253-2259, 2006.

PENNING, P.D.; PARSONS, A.J.; NEWMAN, J.A. et al. The effects of group size on grazing time in sheep. Applied Animal Behaviour Science, v.37, n.2, p.101-109, 1993.

PENNING, P.D.; PARSONS, A.J.; ORR, R.J. Intake and behaviour responses by sheep to changes in sward characteristics under continuous stocking. Grass and Forage Science, v.46, n.1, p.15-28, 1991.

PRACHE, S.; PEYRAUD, J. Foraging: behaviour and intake in temperate cultivated grassland. In: INTERNATIONAL GRASSLAND CONGRESS, 19., 2001, São Pedro. Proceedings... São Paulo: [s.n.], 2001. p.309-319.

PRACHE, S.; PEYRAUD, J. Préhensibilité de l'herbe pâturée chez les bovines et les ovins. Productions Animales, v.10, n.2, p.377-390, 1997.

RIND, M.I; PHILLIPS, C.J. The effect of group size on the ingestive and social behaviour of grazing dairy cows. Journal of Animal Science, v.68, n.1, p.589-596, 1999.

ROGUET, C.; DUMONT, B.; PRACHE, S. Selection and use of feeding sites and feeding stations by herbivores: A review. Annales de Zootechnie, v.47, n.3, p.225-244, 1998.

ROOK, A. J.; DUMONT , B.; ISSELSTEIN, J.; et al. Matching type of grazing animal to desired biodiversity outcomes - a review. Biological Conservation, v.119, p.137-150, 2004.

RUYLE, G.B.; DWYER, D.D. Feeding stations of sheep as an indicator of diminished forage supply. Journal of Animal Science, v.16, n.2, p.349-353, 1985.

SANTOS, D.T.; CARVALHO, P.C.F.; FREITAS, F.K. et al. Adubação de pastagem natural no Sul do Brasil: 1. Efeito do Nitrogênio sobre a produção primária. In: GRASSLAND ECOPHYSIOLOGY AND GRAZING ECOLOGY, 2., 2004, Curitiba. Proceedings.. Curitiba: UFPR/Macromedia, [2004]. (CD-ROM).

SILVA, S.C.; CARVALHO, P.C.F. Foraging behaviour and herbage intake in the favourable tropics/sub-tropics. In: McGILLOWAY, D.A. (Ed.) Grassland: a global resource. Dublin, 2005. p.81-95.

STATISTICAL ANALYSIS SYSTEM - SAS. SAS/STAT User's guide 8.0. Cary: SAS Institute Inc., [1999]. (CD-ROM).

THARMARAJ, J.; WALES, W.J.; CHAPMAN, D.F. et al. Defoliation pattern, foraging behaviour and diet selection by lactating dairy cows in response to sward height and herbage allowance of a ryegrass dominated pasture. Grass and Forage Science, v.98, p.225-238, 2003.

UNGAR, E.D. Ingestive behaviour. In: HODGSON, J.; ILLIUS, A. (Eds.) The ecology and management of grazing systems Oxford: Oxford University Press, 1996. p.185-218.

UNGAR, E.D.; NOY-MEIR, I. Herbage intake in relation to availability and sward structure: grazing processes and optimal foraging. Journal of Applied Ecology, v.25, n.1, p.1045-1062, 1988.

WALLIS DE VRIES, M.F.; LACA, E.A.; DEMMENT, M.W. The importance of scale of patchiness for selectivity in grazing herbivores. Oecologia, v.121, p.355-365, 1999. 